\title{
Heterosis of some sperm production traits in hybrid boars
}

\author{
L. HOUSKA, R. SILER, J. PAVLIK and J. BAZANT \\ Research Institute of Animal Production, 251 6I Prague 10, \\ Uhr̈inèves, Czechoslovakia
}

The Belgian Landrace $\times$ Duroc hybrid boars are compared with the parental purebred breeds as to the ejaculate volume, sperm concentration and total sperm number in ejaculate, and the abnormal sperm percentage. Heterosis effect was determined for each of these traits. The hybrid boars had a heterosis effect of $24.2 \mathrm{p} .100$ for the total sperm number, $11.2 \mathrm{p} .100$ for ejaculate volume, $10.3 \mathrm{p} .100$ for sperm concentration, and $3.57 \mathrm{p}$. 100 for sperm motility. A negative heterosis effect $(-2$ p. 100) was obtained only for the abnormal sperm percentage. The results show that it is advantageous to use hybrid boars in A.I. and in natural breeding.

\section{Allotype Nsi-marker of blood serum beta-globulins in sheep}

\author{
Elisabeth SKIBA \\ Institute of Zootechnics, Department of Immunogenetics, \\ 32-083 Balice near Kraków, Poland
}

The successive marker of blood serum proteins in sheep, preliminary denoted Nsi, was detected and characterized. The anti-Nsi isoprecipitins were obtained after immunizations of proteins from haemolytic immunoserums coated on recipient's red blood cells. Freund's complete adjuvant was used. Results obtained indicate, that antigen Nsi is beta-globulins marker of about 200000 daltons molecular weight, and conditioned by autosomal gen.

\section{Production of highly inbred salmonids by gynogenesis}

\author{
T. REFSTIE \\ Department of Animal Genetics and Breeding, \\ Agricultural University of Norway, $1432 \AA s-N L H$, Norway
}

The possibilities to produce inbred lines of Atlantic salmon (Salmo salar) and rainbow trout (Salmo gairdneri) using irradiated sperm and heat shock are studied. Effect of temperature level, duration of shock and time course from insemination to heat shock are investigated. All temperatures used increase frequency of gynogenetic frys. Time course from insemination to heat shock do not influence the results. Rainbow trout gave higher frequencies of gynogenetic frys than Atlantic salmon at all temperatures used. The highest frequencies of gynogenetic frys were produced when Atlantic salmon and rainbow trout eggs were heat shocked at 24 and 26 "C, respectively. The rate of gynogenetic frys produced are high enough for production of large number of inbred lines. 